\title{
As escolas quilombolas em Goiás - retrato da escola na relação com o poder público dos anos 2000
}

Cristiane Maria Ribeiro *

Mariana Cunha Pereira ${ }^{* *}$

\section{Resumo}

Este manuscrito tem por objetivo discutir sobre o quadro político em que se encontram as escolas quilombolas do estado de Goiás. Situamos essas escolas no contexto da política de reconhecimento das terras quilombolas e desse modo expressa que os sujeitos sociais interagem na relação com o poder público, o que significa dizer que a escola está inserida numa realidade sócio-política de tensão e conflitos. Acreditamos que a relação escolas quilombola e poder público, no atual governo do estado de Goiás têm refletido uma situação de descontinuidade da política pública. Para elaborar essa reflexão nos embasamos em pesquisas de campo realizadas sobre as escolas quilombolas dos quilombos Cavalcante e Mesquita. Portanto, o relatório da pesquisa intitulada: POLÍTICAS PÚBLICAS DE EDUCAÇÃO PARA COMUNIDADES RURAIS NEGRAS - Quilombos (Brasil)-Levantamento Socioeducacional Sobre os Professores das Escolas Quilombolas em Goiás e levantamentos realizados junto ao setor de educação do campo da Secretaria de Educação de Goiás foram fundamentais para a constituição deste. Por fim dizer que encontramos nas escolas tais problemas: qualificação dos educadores, infra-estrutura, sem acesso a internet e sem recursos didáticos mais simples, porém, identificamos sujeitos sociais participativos e de muito engajamento político no seu quer fazer docente.

Palavras chave: Educação Escolar, Escola, Quilombo e Poder Público.

The quilombola's schools in Goiás - a portrait of the school in the relationship with the government in the 2000's

\section{Abstract}

This paper aims to discuss the political context of quilombola's Schools in the state of Goiás. We situated those schools in the political context of recognizing those lands of ex-Slaves communities and then expressed that social subjects interect with the government, and it means to say that the school is inserted in social-political context of tensions and conflicts. We believe the relationship between quilombola's schools and the current government in the state of Goiás has exerted the a

\footnotetext{
Professora do Instituto Federal Goiano/Urutaí. Doutora em Educação pela Universidade Federal de São Carlos (2005). Mestre em Educação pela Universidade Federal de Uberlândia (2000). Graduada em Pedagogia pela Universidade Federal de Goiás (1995). E-mail: crismariaufg@hotmail.com

** Professora da Faculdade de Educação da Universidade Federal de Goiás. Doutora em Antropologia Antropologia da América Latina e Caribe (2005/UnB). Mestre em Educação (1995/UnB). Graduada em Ciências Sociais na Universidade Federal do Ceará (1985/UFC). E-mail: mcunhap@yahoo.com.br
} 
situation of discontinuity of public policy. In the methodology it was used field researches about the quilombola's schools and the ex-slaves communities in the cities of Cavalcante and Mesquita. Accordingly, the repport "EDUCATION PUBLIC POLICIES ADRESSED TO RURAL BLACK COMMUNITIES - quilombos (Brasil) - Socioeducational survey about teachers of quilombola's schools in Goiás" and the surveys we colected at the deppartment of rural education in the Secretary of Education of Goiás were the key to produce the discussions in here. For the results we found problems in the schools as: Professinal qualification for the professors, infrastructure, nor access for the internet nor other basic teaching resources. However, we found participatory social subjects with strong political engagement in their teaching practices.

Key Words:Educational School, School, Quilombo and government.

\section{Contexto Social e Político do Tema}

A Educação escolar de uma forma mais ampla retrata o que as políticas públicas aqui denominadas de políticas educacionais orientam em termos do sistema de ensino. Viera (2000) afirma que: A politica educacional não resulta apenas da deliberação exclusiva da burocracia. Antes se constitui como fonte de complexa relação que se estabelece entre o Estado e as forças sociais que logram êxito em fazer valer seus interesses junto ao aparato estatal. (1990:1 a 3 In: 2000). Ainda que seja claro o forte processo de privatização da educação nos sistemas de ensino dos países endividados com os grupos financeiros internacionais, ainda assim, há que se reconhecer esse significado de política educacional. Esta é a compreensão que embasa este artigo.

Neste texto pretendemos mostrar um diagnóstico da situação sócio-educacional das escolas quilombolas do estado de Goiás a fim de que possamos discutir como se dá o fazer pedagógico e de que modo se entrelaçam as relações sociais e políticas internas e externas ao quilombo. Por conseguinte, em que pese o recorte da discussão - escolas quilombolas - pretendemos identificar em que medida está o planejamento sobre a escola do campo ou a política educacional do campo em Goiás?

Passados os 500 anos da história desse país, identifica-se em quase todo o território nacional a existência das comunidades negras tanto na área rural quanto na área urbana, às quais, a literatura especializada, as políticas públicas e os movimentos sociais têm elaborado uma série de ações e análises para melhor entendê-las e visibilizá-las no cenário nacional.

No entanto, é necessário dizer que a história dessas comunidades negras nas duas últimas décadas do século XX, tem mostrado que a política pública de maior relevância para essa população é sem dúvida a regularização das terras. Tanto é verdade que existem hoje cerca de 1.408 (mil quatrocentos e oito) comunidades quilombolas 
certificadas no Brasil e outros processos que tramitam em fase de reconhecimento. Os principais órgãos públicos do governo federal encarregados dessa demanda são: a Fundação Palmares, o Instituto nacional de Reforma Agrária; a Secretaria de Promoção da Igualdade Racial, o Ministério da Educação, entre outros. O quadro abaixo mostra o número de comunidades certificadas em Goiás.

Fig.01 - quadro das comunidades rurais quilombolas de Goiás/2014

\begin{tabular}{|c|c|c|c|c|c|c|}
\hline 60 & APARECIDA DE GOIÂNIA & 5201405 & JARDIM CASCATA & $01420.000120 / 2007-11$ & Certificada & 02/03/2007 \\
\hline Go & BARRO ALTO & 5203203 & ANTÔNIO BORGES & $01420.001174 / 2007-96$ & Certificada & $09 / 12 / 2008$ \\
\hline 60 & BARRO ALTO & 5203203 & FAZENDA SANTO ANTÔNIO DA LAGUNA & $01420.002306 / 2006-16$ & Certificada & $13 / 12 / 2006$ \\
\hline 60 & $\begin{array}{l}\text { BARRO ALTO ISANTA RTA } \\
\text { DO NOVO DESTINO }\end{array}$ & $\begin{array}{r}5203203 \mid \\
5219456 \\
\end{array}$ & TOMÁS CARDOSO & $01420.001175 / 2007-31$ & Certificada & 04/08/2008 \\
\hline 60 & CAMPOS BELOS & 5204904 & BREÃO & $01420.001212 / 2006-20$ & Certificada & $13 / 03 / 2007$ \\
\hline 60 & CAMPOS BELOS & 5204904 & TAQUARUSSU & $01420.001213 / 2006-74$ & Certificada & $13 / 03 / 2007$ \\
\hline 60 & $\begin{array}{l}\text { CAVALCANTE | MONTE } \\
\text { ALEGREDEGO|ÁS }\end{array}$ & $\begin{array}{l}5205307 \mid \\
52135091\end{array}$ & KALUNGA & 01420.000298/1998-11 & Certificada & $19 / 04 / 2005$ \\
\hline GO & $\begin{array}{l}\text { CIDADE OCIDENTAL } \\
\text { BRASIILA): }\end{array}$ & $\begin{array}{l}5205497 \mid \\
5300108\end{array}$ & MESQUITA & 01420.000359/1998-31 & Certificada & 07/06/2006 \\
\hline 60 & COUNAS DOSUL & 5205521 & JOSÉ DE COLETO & 01420.000010/2009-11 & Certificada & $05 / 05 / 2009$ \\
\hline 60 & CRISTALINA & 5206206 & INOCÊNCIO PEREIRA DE OLVEIRA & 01420.001463/2009-57 & Certificada & $24 / 03 / 2010$ \\
\hline GO & CROMÍNIA & 5206503 & NOSSA SENHORA APARECIDA & 01420.001148/2006-87 & Certificada & 07/06/2006 \\
\hline 60 & FLORES DE GOIÁS & 5207907 & FLLRES VELHA & $01420.015245 / 2013-86$ & Certificada & $18 / 03 / 2014$ \\
\hline 60 & IACIARA & 5209903 & EXTREMA & $01420.000935 / 2014-11$ & Certificada & $18 / 03 / 2014$ \\
\hline Go & IACIARA & 5209903 & POVOADO LEVANTADO & 01420.001903/2010-18 & Certificada & $19 / 09 / 2013$ \\
\hline 60 & IACIARA | POSSE & $\begin{array}{l}5209903 \mid \\
5218300\end{array}$ & BACO PARI & $01420.000559 / 2006-55$ & Certificada & $07 / 06 / 2006$ \\
\hline 60 & MIMOSO DE GOIÁS & 5213053 & MIMOSO DE GOIÁS & $01420.007524 / 2013-76$ & Certificada & 19/09/2013 \\
\hline 60 & MINAÇU & 5213087 & MINAÇÚ (SÃo FÉLIX) & $01420.000562 / 2006-79$ & Certificada & $12 / 05 / 2006$ \\
\hline 60 & MINEIROS & 5213103 & BURACĂo & $01420.002664 / 2006-29$ & Certificada & $13 / 12 / 2006$ \\
\hline GO & MINEIROS & 5213103 & CEDRO & $\begin{array}{l}\text { O1420.000099/1999-01 } \\
\text { Esta como Documento no }\end{array}$ & Certificada & $08 / 06 / 2005$ \\
\hline 6o & MONTE ALEGRE DE GOIÁS & 5213509 & PELOTAS & $01420.000244 / 2005-27$ & Certificada & $28 / 07 / 2006$ \\
\hline 60 & NIQUELANNDIA & 5214606 & RUFINO FRANCISCO & 01420.011796/2011-17 & Certificada & $24 / 09 / 2014$ \\
\hline Go & NOVA ROMA & 5214903 & QUILOMBOLA DO MAGALHĀES & $01420.000121 / 2004-13$ & Certificada & 04/06/2004 \\
\hline 60 & PADRE BERNARDO & 5215603 & SUMIDOURO & $01420.005777 / 2013-13$ & Certificada & 19/09/2013 \\
\hline Go & $\begin{array}{l}\text { SANTA RITA DO NOVO } \\
\text { DESTINO }\end{array}$ & 5219456 & POMBAL & $01420.000307 / 1999-46$ & Certificada & $19 / 04 / 2005$ \\
\hline Go & $\begin{array}{l}\text { SANTA RITA DO NOVO } \\
\text { DESTINO }\end{array}$ & 5219456 & BALBINO DOS SANTOS & $01420.004623 / 2014-87$ & Certificada & $24 / 09 / 2014$ \\
\hline Go & SÃO JOÃO D ALLANÇA & 5220009 & FORTE & $01420.000288 / 2008-08$ & Certificada & 05/03/2008 \\
\hline Go & SÃO LUIZZ DO NORTE & 5220157 & PORTO LEUCÁDIO & 01420.002905/2005-59 & Certificada & 20/01/2006 \\
\hline 60 & SILVÂNIA & 5220603 & ALMEIDAS & $01420.000522 / 2004-65$ & Certificada & $25 / 05 / 2005$ \\
\hline 60 & TRINDADE & 5221403 & VÓ RITA & $01420.000446 / 2009-01$ & Certificada & $05 / 05 / 2009$ \\
\hline 60 & URUAÇU & 5221601 & JOÃO BORGES VIEIRA & $01420.000011 / 2009-58$ & Certificada & $05 / 05 / 2009$ \\
\hline Go & Alto Paraiso & 5200605 & POVOADO MOINHO & 01420.013360/2014-05 & Certifceda & 29/12/2015 \\
\hline GO & Piracanjuba & 5217104 & ANA LAURA & 01420.007528/2014-35 & Certifcada & 29/12/2015 \\
\hline 60 & Professor Jamil & 5218391 & BOANOVA & 01420.011634/2014-13 & Certifcada & 29/12/2015 \\
\hline
\end{tabular}

Fonte: www.palmares.gob.br acesso em 15 de março de 2016 
O processo que inseriu as comunidades negras na luta pela titulação da terra as encaminhou, também, a se organizarem em busca de Políticas Educacionais a fim de que, com o exercício do direito à Educação, esses sujeitos melhor se instrumentalizassem para desmistificar o papel do negro na história do país e melhor fundamentassem suas reivindicações com base numa identidade afrodescendente. Isso veio ao encontro das preocupações tanto dos movimentos negros quanto daqueles que, na academia, estão realizando pesquisas sobre educação da população negra e quilombola.

Desse modo, e diante desse cenário, transformamos em questões nossas percepções sobre a política educacional para a escola quilombola do campo. Daí nos colocamos a pensar: Que modelos de escola existem nesses quilombos? Como se estruturam no aspecto físico e quanto aos recursos didáticos e humanos? De que modo os fazeres e os saberes pedagógicos se organizam e tomam lugar na dinâmica escolar?

2. Quais discussões são pertinentes para pensar a educação em escolas quilombolas?

GONÇALVES \& SILVA (1998) categorizaram os estudos sobre relações raciais e educação entre os anos 80 e 90 apresentados na ANPED (Associação Nacional de Pós-graduação e Pesquisa em Educação) relatando o predomínio dos seguintes assuntos: identidade de crianças negras; estereótipos e preconceitos nos livros didáticos; identidade étnica de trabalhadores rurais; rituais pedagógicos enquanto mecanismos de discriminação racial; formação e trajetória de professores negros e avaliação de experiências no campo da multiculturalidade.

Além do aumento das pesquisas sobre a educação da população negra também é perceptível nos documentos oficiais o chamado para as escolas "posicionarem-se em relação a esses fatos, mediante informações corretas, cooperando no esforço de superação do racismo e da discriminação (PCNs, 1997, p.45). Podemos mencionar, entre estas iniciativas, a promulgação da Lei 10639/2003 que altera a LDB (Lei Diretrizes e Bases da Educação Nacional) 9394/1996 estabelecendo a obrigatoriedade do ensino de história e cultura afro-brasileira e africana na Educação Básica.

Na esfera acadêmica tivemos o concurso "Negro e Educação" que trouxe subsídios importantes para a ampliação do conhecimento tanto teórico quanto empírico sobre o tema. HADDAD (2002, p.10) considerou que o concurso "Negro e Educação" é muito importante haja vista que na primeira edição do concurso ocorrida no período de 1999-2000 foram apoiados financeiramente dez projetos. No período 2001-2003, a 
segunda edição apoiou 15 trabalhos universitários de várias partes do Brasil. E a terceira edição contemplou 20 projetos.

Ainda na esfera acadêmica, é digno de nota a criação do Grupo de Estudos Relações Raciais/Étnicas e Educação pela ANPED (Associação Nacional de Pós-graduação e Pesquisa em Educação) em 2001, e sua transformação em Grupo de Trabalho a partir de 2004.

Esse movimento de atenção à situação educacional da população negra é reforçado pela criação da Associação Brasileira de Pesquisadores Negros que organiza o Congresso de Pesquisadores Negros com o objetivo principal de congregar estudiosos que tratem da problemática racial, direta ou indiretamente, ou se identifiquem com os problemas que afetam a população negra no Brasil.

Nesse contexto, surgem também preocupações em investigar a situação de comunidades rurais como bem observa RIBEIRO (2005, p.180-181).

As pesquisas que tiveram como foco de análise as relações raciais em territórios/comunidades de predominância afrodescendentes sejam elas urbanas (bairros) ou rurais, mostram que nestes espaços também as relações raciais são complexas, mostram que a despeito de terem consciência do seu pertencimento étnico-racial, e que neste espaço são maioria, também percebem a negação pela sociedade brasileira de seu grupo e procuram com isso se comportar como brancos. Algumas mostram por outro lado um grande potencial de mobilização no sentido de afirmar e legitimar os valores negros. (RIBEIRO, 2005, p180-181)

Temos o trabalho de PARO, OLIVEIRA E VELLOSO (2007) que falam especificamente sobre a educação na comunidade Kalunga. Nele, os autores se detiveram a analisar a situação educacional da comunidade do Engenho II integrante do território Kalunga. Na investigação, detectou-se que existe a consciência dos familiares e das crianças e adolescentes quanto à importância do ensino oferecido pela escola formal, sobretudo na construção da autonomia do indivíduo na sociedade, o que significa reconhecer a capacidade dessas pessoas de tomarem decisões conscientes em todos os campos de sua vida e, sobretudo, nas relações estabelecidas com as pessoas de fora da comunidade. Entretanto, a relação entre o que se aprende na escola e a sua aplicação no cotidiano dos quilombolas pouco se pode aferir. Os estudantes não conseguem associar um aprendizado ao outro devido, é claro, à dissociação entre os saberes aprendidos na comunidade - ligado ao trato com a terra, ao significado simbólico do território associado à ancestralidade e à identidade étnico-racial, bem como aos ritu- 
ais de celebração da colheita, como a festa de Nossa Senhora das Neves - e os saberes oferecidos nos conteúdos curriculares formais.

As autoras mencionam que no Brasil, segundo o Censo Escolar de 2004, existem 49.722 estudantes matriculados em 374 escolas localizadas em áreas de remanescentes de quilombos, sendo que $62 \%$ das matrículas estão concentradas na região Nordeste. O MEC vem construindo e equipando escolas em áreas rurais dos remanescentes de quilombos, através do Fundo de Fortalecimento da Escola (FUNDESCOLA), para que estados e municípios levem o ensino a estas populações com uma metodologia que deverá seguir o princípio de ensino da Escola Ativa. O projeto arquitetônico elaborado pelo FUNDESCOLA oferece salas planejadas que obedecem aos padrões mínimos de funcionamento, prevendo também a construção da "Casa do Professor", pois estão em áreas de difícil acesso aos professores; a contratação dos mesmos é garantida pelos municípios. (grifo nosso).

\section{O Contra-senso em Goiás: fechamento de escolas no campo}

Em Goiás temos dificuldades de entender o diagnóstico das escolas quilombolas do campo, no que diz respeito a: quantas, quais, onde estão localizadas e quem são os profissionais que trabalham nessas escolas. Porém, durante a pesquisa realizada por nós em 2012, intitulada: POLÍTICAS PÚBLICAS DE EDUCAÇÃO PARA COMUNIDADES RURAIS NEGRAS - Quilombos (Brasil)-Levantamento Socioeducacional Sobre os Professores das Escolas Quilombolas em Goiás, conseguimos uma sistematização junto ao setor de Educação do Campo da Secretaria Estadual de Educação.

Nos três municípios os professores que trabalham nas escolas municipais dentro ou fora da área quilombola, mas atendendo aos alunos Kalunga são professores contratados e com nível de magistério. Já entre os professores das escolas estaduais Calunga que estão dentro da área, no caso são cinco escolas, encontramos na ocasião da pesquisa quatro professores estudando no curso de graduação Licenciatura do Campo ofertado pelo Campus Planaltina da Universidade de Brasília.

Uma vez que os dados sobre as escolas quilombolas estão diluídos nos dados mais amplos sobre as escolas do campo em geral, tivemos como estratégia na pesquisa realizada estabelecer uma amostra, e a partir delas realizar as seguintes questões: quem é esse professor? Como ele se organiza no cotidiano da escola? Que dificuldades enfrenta? Que outras atividades exercem para completar a renda familiar? E sobre a escola: Que modelos de escola existem nesses quilombos? Como se estrutura no aspecto físico e dos recursos didáticos e humanos? Situando as entrevistas entre as 
comunidades Kalunga, dos três municípios, mas, considerando também as entrevistas com professores/gestores de Campos Belo e Mesquita.

Entre os Kalunga, que são um povo cujo território se distribui em três municípios formando pequenas comunidades, existem escolas de ensino fundamental distribuídas entre o território, mas, as escolas quilombolas estaduais, que evidentemente atendem majoritariamente o ensino médio são apenas : intituladas - Calunga I, II, III, IV e V elas também atendem a educação infantil e o ensino Fundamental, dado a necessidade da área onde estão localizadas. Todos os prédios em que estão as escolas abaixo elencadas são de propriedade do Estado.

Fig. 02 - Quadro distribuição dos municípios versus escolas estaduais calungas

\begin{tabular}{|c|c|}
\hline Municípios & Escolas \\
\hline CAVALCANTE & Escola Estadual Calunga I \\
\hline MONTE ALEGRE & $\begin{array}{l}\text { Escola Estadual Reunida Calunga II } \\
\text { Escola Estadual Calunga IV } \\
\text { Escola Estadual Calunga V }\end{array}$ \\
\hline TERESINA DE GOIÁS & Escola Estadual Calunga III \\
\hline
\end{tabular}

Fonte: Departamento de Educação Quilombola /SEDUCE, julho de 2014.

O colégio apresentava uma estrutura regular. Nele são ministradas aulas para a alfabetização, ensino fundamental, e ensino médio, que foi há pouco tempo implantado. A estrutura física obedece um modelo adotado pelas escolas da rede estadual por todo o estado; duas salas de aula, uma ao lado da outra, uma área (um roll) entre as salas e os compartimentos da cozinha e do almoxarifado, sendo que ao fundo dessa área tem um pequeno quarto onde está improvisada a biblioteca. A cozinha tem um janelão com bancada por onde é entregue a merenda escolar, para as crianças maiores. As pequenas recebem a merenda trazida pelas professoras em suas carteiras na sala de aula.

Entrevistamos cinco professoras, todas tinham perfil jovem. A maioria delas relatou não ter cursado a graduação, apenas o ensino médio e estarem traba- 
lhando por regime de contrato temporário do Município ou Estado. As professoras que possuem contrato no município ministram aulas para a Educação Infantil e o Ensino Fundamental, o qual funciona à tarde. E as professoras que possuem contrato no Estado ministram aulas do Ensino Médio. Nas entrevistas as professoras apresentaram muito interesse em fazer um curso superior, de Pedagogia, preferencialmente.

Em Cavalcante, visitamos também a Secretaria da Igualdade Racial que naquele momento passava por mudança no seu quadro interno. Mesmo assim obtivemos algumas informações e fomos bem recebidos. As informações acerca das escolas quilombolas administrada pela Secretaria de Educação do Estado de Goiás/SEDUC estavam muito dispersas nas respostas das professoras. Daí sentimos necessidade de averiguar alguns dados junto a Sub-Secretaria daquela região que funciona no município de Campos Belos, cidade próxima a Cavalcante, cerca de 778, $1 \mathrm{~km}$ da Capital. Ali foram realizadas entrevistas junto a Sub-Secretaria de Educação e a Secretaria Municipal de Campos Belos.

Esses gestores utilizam a terminologia "escolas rurais" e reconhecem que antes existiam mais escolas rurais no município de Campos Belos e que os alunos dessas escolas foram removidos para as escolas da zona urbana apenas pelo critério da oferta de vagas, ou, quando muito, apreciando-se a distância do lugar de origem do aluno com a localização da escola. Segundo a gestora que nessa entrevista estava se referindo apenas as escolas municipais, ou seja, aquelas sob a tutela da prefeitura: "....isso ocorreu porque a Secretaria da época entendia que na zona rural o aluno recebia uma educação inferior ao aluno da zona urbana". No seu relato ela aponta para uma concordância com o encaminhamento quando diz: "..... gente percebe que realmente esses alunos estavam recebendo uma educação inferior...era turma multisseriada, então, era um trabalho apenas orientado pelo professor regente, não havia outros profissionais envolvidos, era um trabalho muito difícil para o professor....então foi o encaminhamento que se encontrou para resolver o baixo nível de educação que os alunos estavam recebendo".

Tanto nas entrevistas com aqueles que representam o poder público quanto nas entrevistas com professores dos quilombos pesquisados não encontramos nenhuma menção a construção de "casa do professor". Em geral os professores que não são das comunidades quilombolas fazem uma migração diária se a comunidade for próxima e de fácil acesso a sede do município em que está inserida. Esse é o exemplo de uma professora que trabalha na escola da comunidade Fazenda Ema, essa professora nos disse que faz esse ir e vir todos os dias de bicicleta, pois tem marido e filhos e não 
pode dormir ali. Caso não seja perto e o acesso for difícil o professor faz essa migração mensalmente, exatamente no dia em que vem receber o salário na cidade. Nessa condição, em geral, encontramos mais professores homens, ou professoras mulheres não casadas. Esses professores possuem família que moram na sede do município e para lá eles retornam nos feriados, finais de semana prolongados, férias ou na ocasião em que vão buscar seus salários e fazer compras pessoais básicas.

Os dados não são diferentes quando mudamos o lugar da observação. As pesquisas realizadas também no quilombo do Cedro, localizado a quarenta minutos da cidade de Mineiros, também, nos mostra esse distanciamento entre poder público e a comunidade local o que nos mostra a necessidade de educação escolar para as crianças quilombolas. Vejamos um trecho de um dos relatórios parciais da pesquisa realizada ali em 2010:

\begin{abstract}
A Comunidade do Cedro contava com uma pequena escola que oferecia a primeira fase do ensino fundamental. As aulas eram ministradas por uma única professora em uma única sala de aula para todos os alunos. A comunidade, mesmo afirmando que a qualidade da educação oferecida era ruim, preferia a comodidade de ter uma escola dentro da área, evitando o deslocamento para a cidade. Hoje essa escola está desativada e a Comunidade freqüenta as escolas estaduais e municipais no município de Mineiros. Algumas famílias vivem hoje na cidade por conta do trabalho e também da escola, diminuindo a quantidade de famílias presentes na região do Cedro. (Relatório parcial da visita de campo realizada em set./2010).
\end{abstract}

No quilombo Mesquita que fica a $08 \mathrm{Km}$ da Cidade Ocidental/DF, a escola não está situada dentro do quilombo está do lado de fora, porém, muito próxima. No entanto, a entrevista com a direção e os professores demonstraram que eles têm consciência que seu alunado é composto por crianças quilombolas. Nesse sentido, na entrevista a diretora denomina a escola de "escola quilombola”. Também por esse motivo a identidade negra está representada em painéis, atividades expostas na parede das salas e no desenho que define os banheiros de meninas e de meninos.

Essa é uma escola que tem um diferencial tanto de infra-estrutura quanto de corpo docente. A escola estava muito bem equipada: armários, mesa na sala dos professores, carteiras escolares em bom estado, salas arejadas, quadro de giz em bom estado e tinha uma máquina copiadora na sala da diretora que servia à reprodução das atividades pedagógicas. $\mathrm{Na}$ ocasião das entrevistas da pesquisa que desenvolvíamos a 
Escola se preparava para planejar uma apresentação no desfile de sete de setembro. Na fala da líder comunitária que nos acompanhava na visita à escola percebemos muita satisfação com o convite, dando pistas de que o convite veio pela identificação de que aquela era uma escola quilombola e desse modo poderia realizar uma apresentação que evocasse o sentido de ser descendente de escravos, mas, que também apresentasse o quilombo de Mesquita como um forte componente da economia local. Isso por que no Mesquita se produz um doce que é referência na região e que demarca a identidade dos quilombolas dali. Trata-se do doce marmelada. A escola, portanto, naquela comunidade tem uma função social muito definida, segundo o nosso olhar ao estabelecermos relação entre a observação de campo e as entrevistas, qual seja a função de afirmar a identidade afrodescendente e quilombola.

\section{A título de considerações finais:}

A experiência com as pesquisas acumuladas nas áreas quilombolas citadas, somadas aos eventos da discussão de construção das diretrizes curriculares nacionais para a construção da educação escolar quilombola, em uma das audiências públicas, realizada em Brasília (2014), e embasada por uma bibliografia que tenta dialogar com essa realidade heterogênea e dinâmica que é a histórias dos povos quilombolas do Brasil, nos levam a entender o quão é social e simbólico o papel da escola como lugar de afirmação ideológica positiva da identidade quilombola.

No entanto, quando isso não ocorre é por que os sujeitos que constituem a escola não se veem como quilombolas, então, a escola ao invés de ser um campo de atuação, de ressonância, de exercício do pertencimento, ela passa a ser o espaço da negação dos valores, da história, dos mitos.

Nossa percepção pelas visitas de campo e entrevistas é que as escolas quilombolas vivenciam uma tensão entre a influência do que definem e defendem suas lideranças e o que vem de fora como determinação do poder público. Há uma tensão entre o que se quer e o que deve ser. E há também, uma diferença entre um tempo em que se recebiam as determinações do poder público de modo inquestionável e o tempo de hoje, anos 2000, em que em algumas comunidades as professoras são mulheres quilombolas que se tornaram lideranças e que estão em processo de qualificação universitária, refletindo sobre sua identidade social e seu papel local. Professoras que da condição de ex-alunas quilombolas agora assumem seu papel de educadoras frente às escolas locais. 


\section{Referências}

ACEVEDO MARIN, R. E. Caminhos Transversais: Território e Cidadania Negra. In: Terra de Quilombos (org.) O’Dwyer, Eliane Catarino. Associação Brasileira de Antropologia: CFCH/UFRJ, 1995.

ALMEIDA, A. W. B. de. Os Quilombos e as Novas Etnias. In: Quilombos no Brasil, Fundação Cultural Palmares: Brasília, 1999.

AZEVEDO, J. M. L. de. A Educaçao Como Política Pública. Campinas;SP, Autores Associados, 1997.(Coleção Política do Nosso Tempo).

BRASIL. Secretaria de Educação Fundamental. PCNs. Brasília:MEC, 1997.

CASTELLS, M. O Poder da Identidade. V. II, $2^{\text {a } . e d ., ~(t r a d .) ~ K l a u s s ~ B r a n d i n i ~ G e r h a r d t, ~}$ São Paulo: Paz e Terra, 1999.

CONSTITUIÇÃO DA REPÚBLICA FEDERAL DO BRASIL, 1988. Brasilia: Congresso Nacional, 1988.

CONSORTE, J. G. A questão do negro: velhos e novos desafios. São Paulo em Perspectiva, São Paulo, v.5, n.1, 1991. p.85-92

DORIA, S. Z. O Quilombo do Rio das Rãs In: Terra de Quilombos (org.) O’Dwyer, Eliane Catarino. Associação Brasileira de Antropologia: CFCH/UFRJ, 1995.

GONÇALVES, Luiz A. de O. De preto a afro-descendente: da cor da pele a categoria científica. In: BARBOSA, Lúcia Maria de Assunção (orgs.). De preto a Afro-descendente: trajetos de pesquisa sobre negro, cultura negra e relações étnico-raciais no Brasil. São Carlos: EdUFSCAR, 2003.p.15-24.

HADDAD, S. Apresentação do livro Racismo no Brasil. In: ABONG. Racismo no Brasil. São Paulo. 2002.

LEI DE DIRETRIZES E BASE DA EDUCAÇÃO BRASILEIRA. 1996. In: Cadernos de Educação, CNTE: Brasília, 1998..639/2003 
PINTO, R. P. A educação do negro: uma revisão bibliográfica. Cadernos de Pesquisas, São Paulo, n. 62, 1987. p. 3-34

Raça e educação: uma articulação incipiente. Cadernos de Pesquisas, São Paulo, n.80, 1992. p. 41-50

RIBEIRO, C. M. As pesquisas sobre o negro e a educação no Brasil: uma análise de suas concepções e propostas. UFSCAR:SÃO Carlos;SP2005.(Tese de doutorado).

SEVERINO, A. J. Metodologia do Trabalho Científico. 18 a ed., São Paulo: Autores Associados, 1992.

SILVA, P. B. G. e. Movimento Negro, Educação e Produção do Conhecimento de Interesse dos Afro-Brasileiros. 1999.

VIEIRA, S. L. Política Educacional em Tempos de Transição. Brasília:Plano, 2000.

Recebido em: 09 abril 2016.

Aceito em: 20 abril 2016. 